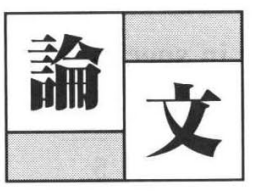

\title{
銅短緎維混入による高導電性プラスチックの開発
}

\author{
野口裕之*・中川威 雄*
}

\section{Development of High Conductivity Plastic Using Short Copper Fiber}

\begin{abstract}
Noguchi, Hiroyuki*/Nakagawa, Takeo*
Many researches are being conducted on conductive plastic for use for static electricity prevention and electromagnetic shielding. The aim of this study is to fabricate a power circuit which allows flow of current to a considerable extent using compression molded conductive plastic. First, to minimize the electric resistance of the conductive plastic, experimentations were carried out on the volume resistivity and formability of a compression molded product containing a high amount of short copper fibers in the resin $(16 \sim 50 \mathrm{vol} \%)$.

The results showed that $2.2 \times 10^{-5} \Omega \cdot \mathrm{cm}$ volume resistivity can be achieved. In the experiment, the composition was adjusted using commercially available conductive materials. We also studied the heat generation characteristics by passing about 10 ampere current through the compression molded material.
\end{abstract}

Key words : Conductive plastic/Short copper fiber/Volume resistivity

\section{1.はじめに}

導電フィラーを樹脂に混入することにより，導電性プラ スチックを製造する試みが盛んに行われるようになったの は，電磁波シールドの問題が登場してきてからであり，今 から抢よそ 20 年前にさかのぼる1.最初はカーボン等の粒 状フィラーを混入したが2)，その後瀻維状フィラーが適し ていることがわかり，カーボン繊維や金属繊維が混入され るようになった ${ }^{33}$. 特にびびり振動切削法" により銅やアル ミ，それらの合金の短繊維が簡単に作れるようになってそ の研究は加速した。微細な直径のステンレス綫維は高価で はあるが，添加量が少なくても繊維長を長くすれば成形性 を低下させずに，必要な導電性が得られることで実用化さ れた5. 特にベルギーのベカルト社で樹脂と瀻維を複合し て押出したペレットを使い分散性の問題を解決したことは 大きな飛躍であった。その後東芝ケミカルでは銅緎維を用 いて類似のペレットを製作する方法を開発した6)。この場 合は図 1 のようにはんだ線を内部に配し射出成形機でペ レットが混練中に銅線同士がはんだで接合する対策をとり 安定した導電材とした。この場合はんだの融点と ABS 樹 脂の軟化温度が近いことをうまく利用している。これらの

\footnotetext{
* 東京大学 生産技術研究所

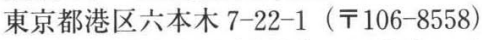

Institute of Industrial Science, University of Tokyo

7-22-1 Roppongi, Minato-ku, Tokyo 106-8558, Japan 1998. 9.17 受理
}

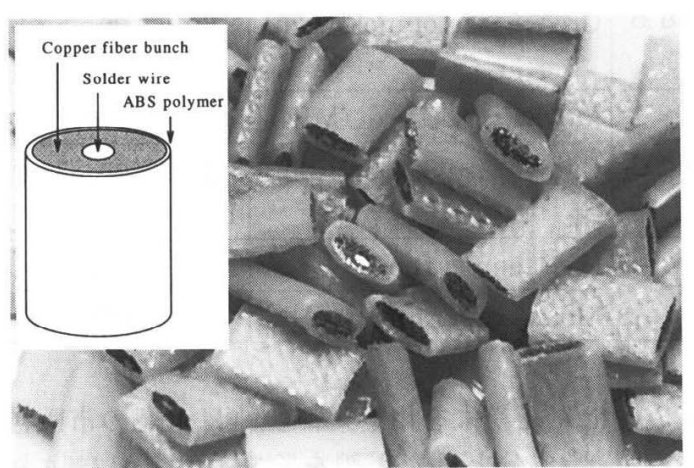

Fig. 1 External view of EMICLEAR master pellet

材料はいずれも電磁波シールド用として開発され，導電性 を表す体積固有抵抗は $10^{-3} \Omega \cdot \mathrm{cm}$ のオーダーである.

本研究は射出成形で立体的な配線を行うことを目標に， より高い導電性をもつ射出成形可能な材料開発を行うこと を目的としている。本報では高い導電性を得る方法として, 銅短緎維とはんだを混入・混練する方法を前提として，こ の方法でどこまで高い導電性が得られるかを明らかとする.

\section{2. 混練方法}

本研究では図 2 のように銅瀻維と ABS 樹脂とはんだを 混練して導電性樹脂を得る方法を採用した。実際には, ABS 樹脂と銅瀻維とはんだの複合体である市販のペレッ ト（東芝ケミカル；エミクリヤSタイプ）に銅㵶維とは んだを添加して，銅瀻維量の割合を増やした。はんだは共 


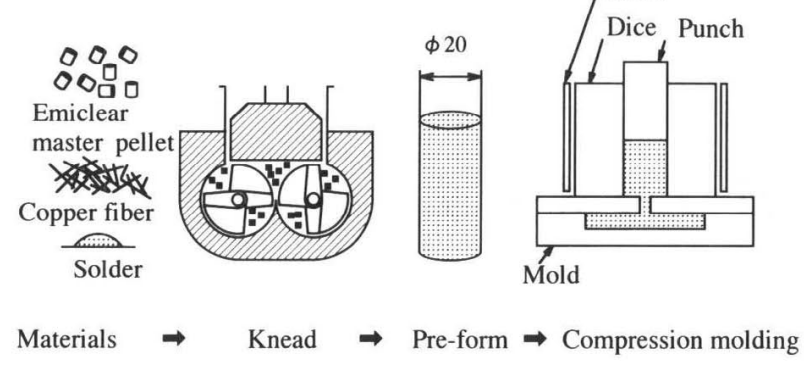

Fig. 2 Fabrication of conductive plastic

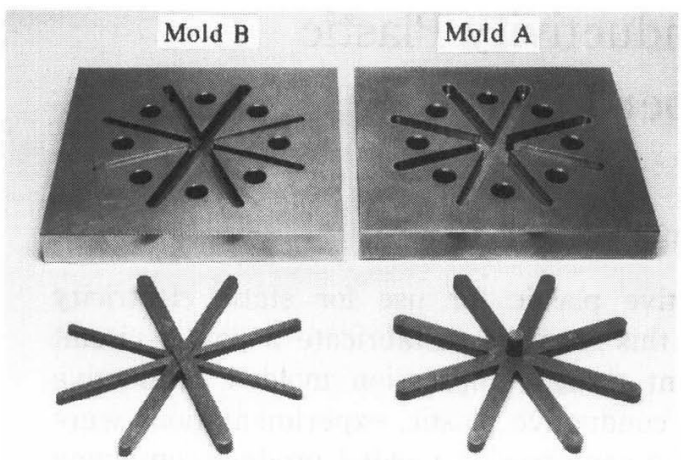

Fig. 3 Mold and molded product

Table 1 Compression molding conditions

\begin{tabular}{c|l|c}
\hline \multirow{2}{*}{ Mold A } & Molding pressure $(\mathrm{MPa})$ & 100,200 \\
\cline { 2 - 3 } & Groove size of mold $(\mathrm{mm})$ & $6 \times 5 \times 90$ \\
\hline \multirow{4}{*}{ Mold B } & Molding pressure $(\mathrm{MPa})$ & 100,200 \\
\cline { 2 - 3 } & Groove size of mold $(\mathrm{mm})$ & $\begin{array}{r}6 \times 6 \times 90,5 \times 5 \times 90, \\
4 \times 4 \times 90,3 \times 3 \times 90\end{array}$ \\
\hline \multirow{2}{*}{ Mold C } & Molding pressure $(\mathrm{MPa})$ & 100,200 \\
\cline { 2 - 3 } & Groove size of mold $(\mathrm{mm})$ & $\begin{array}{c}3 \times 3 \times 90,2 \times 2 \times 90, \\
1 \times 1 \times 90,0.5 \times 0.5 \times 90\end{array}$ \\
\hline & Dice temperature $\left({ }^{\circ} \mathrm{C}\right)$ & 210 \\
\cline { 2 - 3 } & Mold temperature $\left({ }^{\circ} \mathrm{C}\right)$ & $160 \sim 180$ \\
\hline
\end{tabular}

晶組成のはんだ粉末を用いた。繊維は上記の市販複合材よ り ABS 樹脂成分とはんだ線を除去することにより，同一 の直径 $50 \mu \mathrm{m}$, 長さ $6 \mathrm{~mm}$ の銅繊維を準備した。したがっ てはんだは不足量のみ補充した。

混練機は(株森山製作所の 2 軸加圧型混練機（ミックスラ ボ，ML-500）を使用している。混練における回転速度は $50 \mathrm{~min}^{-1}$, ヒーター設定温度 $210^{\circ} \mathrm{C}$, 混練時間 10 分, アル ゴン雲囲気で行った。また，混練後は導電材を円柱状に金 型成形し，これを矩形断面の放射状溝を持つ 3 種類の金型 A (幅×深さ×長さ : $6 \times 5 \times 90 \mathrm{~mm})$, 金型 B $(6 \times 6 \times 90$ $\mathrm{mm}, 5 \times 5 \times 90 \mathrm{~mm}, 4 \times 4 \times 90 \mathrm{~mm}, 3 \times 3 \times 90 \mathrm{~mm})$, 金型 C $(3 \times 3 \times 90 \mathrm{~mm}, 2 \times 2 \times 90 \mathrm{~mm}, 1 \times 1 \times 90 \mathrm{~mm}, 0.5 \times 0.5 \times 90$ mm）に圧縮成形により充填し, その成形体の抵抗值を調 べた. 図 3 に金型 $\mathrm{A}$, 金型 $\mathrm{B}$ とそれぞれの金型による成 形体を示す. 圧縮成形の条件を表 1 にまとめた。

\section{3 . 導電性の評価}

混練した導電性プラスチックの混合割合を表 2 に示す.
Table 2 Contents of copper fiber in specimen

\begin{tabular}{ll|c|c|c|c}
\hline Copper fiber & $(\mathrm{vol} \%)$ & 16.2 & 30 & 40 & 50 \\
\hline Solder & $(\mathrm{vol} \%)$ & 1.6 & 3 & 4 & 5 \\
\hline ABS polymer & $(\mathrm{vol} \%)$ & 82.2 & 67 & 56 & 45 \\
\hline Density & $\left(10^{3} \mathrm{~kg} / \mathrm{m}^{3}\right)$ & 2.4 & 3.6 & 4.5 & 5.3 \\
\hline
\end{tabular}

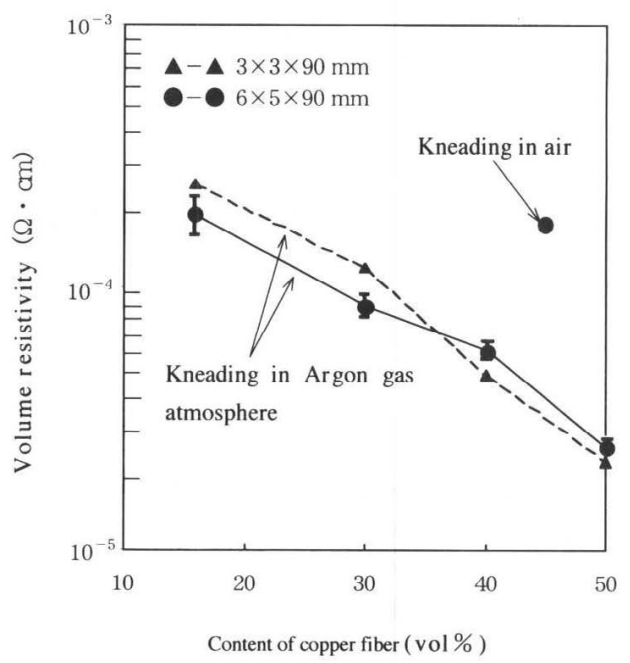

Fig. 4 Relation between content of copper fiber and volume resistivity

Table 3 Dispersion of resistance $(\mathrm{m} \Omega)$ [Mold A]

\begin{tabular}{c|c|c|c}
\hline $\begin{array}{c}\text { Copper fiber } \\
(\mathrm{vol} \%)\end{array}$ & 16.2 & 30 & 40 \\
\hline 1 & 4.7 & 2.8 & 2.0 \\
\hline 2 & 7.0 & 3.0 & 1.7 \\
\hline 3 & 6.5 & 3.0 & 1.8 \\
\hline 4 & 5.7 & 2.5 & 1.8 \\
\hline Average & 6.0 & 2.8 & 1.8 \\
\hline Volume resistivity $(\Omega \cdot \mathrm{cm})$ & $2 \times 10^{-4}$ & $9.3 \times 10^{-5}$ & $6 \times 10^{-5}$ \\
\hline
\end{tabular}

銅繊維含有量は $16.2 \mathrm{vol} \%$ から最高 $50 \mathrm{vol} \%$ まで 4 段階に 変化させた。このときのはんだ量は市販導電性プラスチッ クを参考に銅瀻維の $10 \mathrm{vol} \%$ とした。したがって残りが ABS 樹脂となり, 銅繊維 $50 \mathrm{vol} \%$ の条件では $45 \mathrm{vol} \%$ と半 分以下の樹脂量となる.

図 4 に測定した体積固有抵抗の值を示す。銅繊維の混入 量約 $30 \mathrm{vol} \%$ を境として, 体積固有抵抗值が $10^{-5} \Omega \cdot \mathrm{cm}$ オーダとなっている. 銅のそれが $1.7 \times 10^{-6} \Omega \cdot \mathrm{cm}$ であ るから，銅緎維 $50 \mathrm{vol} \%$ を混入するものでは，ほほ 15 倍 の抵抗值まで近づいている. 図中に示すように, 混練が大 気中で行われると, 抵抗值は大幅に上昇する。これは金属 成分の酸化により生じた酸化被膜のため, 十分な接合が行 われていないことによるものと思われる.

これらの電気抵抗の測定は, 試験片にドリルで穴をあけ, その穴にリード線をはんだ付けして行った。また抵抗值は 8 本の足を持つ放射状成形品の直線端間の 4 本の抵抗測定 を行ったが, その抵抗值のばらつきを表 3 に示す.ばらつ きの最大值は $21 \%$ であり, 比較的ばらつきの少ない值が 
得られていると言えよう。これに対し, 銅繊維を約 $3 \mathrm{vol}$ \%を含む市販の電磁波シールド材では図 5 のようにゲート からの位置および切出し方向などにより導電性にかなり大 きなばらつきが認められるが, 温度変化に対する体積固有 抵抗值の变化はなく安定している。

\section{4. 通電による昇温}

試作した 4 種の導電性プラスチックに対して, 交流電流 を流し試料の表面温度の時間变化を測定した. 各試料の電
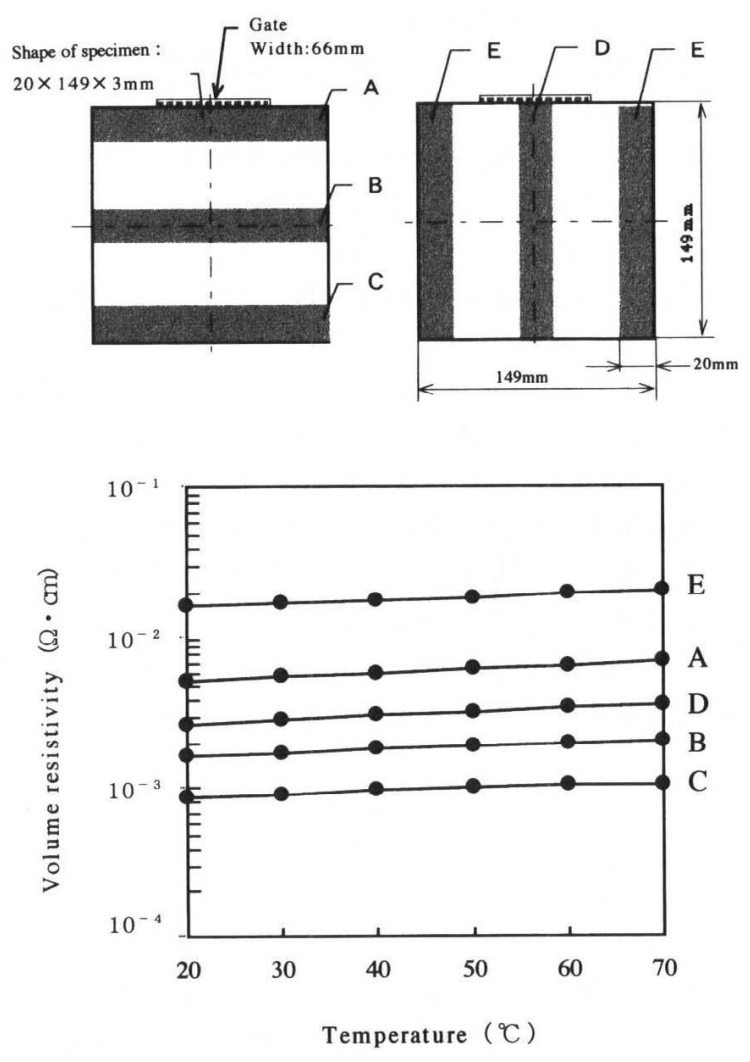

Fig. 5 Measured part and volume resistivity of commercially available conductive plastic (ABS : base resin, copper fiber : 3 vol\%, solder : 0.3 vol\%)

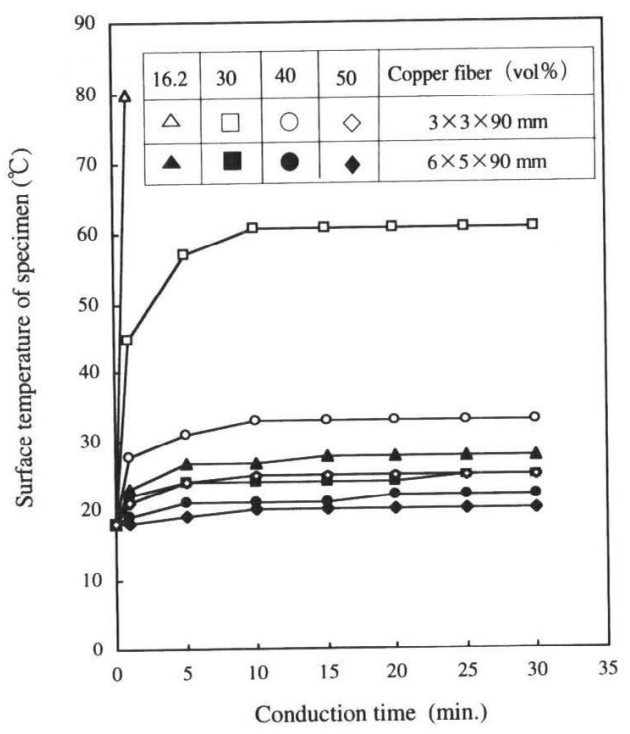

Fig. 6 Tests on heat generation during conduction
流值は約 10 アンペアとした。罒 6 にその結果を示すが, 纎維混入量の少ない $3 \times 3 \mathrm{~mm}$ の細径の成形体を除いては 温度上昇は $10^{\circ} \mathrm{C}$ 程度である. また, 30 分程度連続通電し ても変化が少ない。これは㵶維同士が確実にはんだ付けさ れているからと考えられる.このことは電力系の電線とし て使用できる可能性のあることを示している.

\section{5 . 流動性の評価}

矩形の断面形状を変化させた放射状金型を用いて，圧縮 成形を行い, 銅繊維混入量と流動性の関係を調べた。成形 圧力は $100 \mathrm{MPa}$ と $200 \mathrm{MPa}$ の 2 種類について行い, 金型 への充填状況により流動性を判断した.

その結果を表 4 と図 7 に示すが, 銅緎維が $40 \mathrm{vol} \%$ の のは $2 \mathrm{~mm}$ 角までの成形が叮能であった.しかし， $50 \mathrm{vol}$ $\%$ ものは $4 \times 4 \mathrm{~mm}$ 角のものでも完全な充填はできな かった. $1 \mathrm{~mm}$ 角以下のものはいずれの材料も完全な充填 が成功しなかった，以上の結果より，細線による射出配線 には流動性が劣ることが最大の課題であり，実用のために

Table 4 Success or failure of molding by molding conditions

\begin{tabular}{|c|c|c|c|c|c|c|c|c|}
\hline \multirow{2}{*}{$\begin{array}{c}\text { Molding } \\
\text { pressure } \\
(\mathrm{MPa})\end{array}$} & \multirow{2}{*}{$\begin{array}{c}\text { Copper } \\
\text { fiber } \\
(\text { vol } \%)\end{array}$} & \multicolumn{7}{|c|}{$\begin{array}{l}\text { Groove size of mold } \\
\quad \text { (Square }: \mathrm{mm} \text { ) }\end{array}$} \\
\hline & & 6 & 5 & 4 & 3 & 2 & 1 & 0.5 \\
\hline \multirow{4}{*}{100} & 16 & 0 & 0 & 0 & 0 & 0 & $\times$ & $x$ \\
\hline & 30 & 0 & 0 & 0 & 0 & $\triangle$ & $x$ & $\times$ \\
\hline & 40 & 0 & 0 & 0 & 0 & $\Delta$ & $x$ & $x$ \\
\hline & 50 & $x$ & $x$ & $x$ & $x$ & $x$ & $x$ & $x$ \\
\hline \multirow{4}{*}{200} & 16 & 0 & 0 & 0 & 0 & 0 & $\triangle$ & $x$ \\
\hline & 30 & 0 & 0 & 0 & 0 & 0 & $x$ & $\times$ \\
\hline & 40 & 0 & 0 & 0 & 0 & 0 & $x$ & $\times$ \\
\hline & 50 & 0 & 0 & $\Delta$ & $x$ & $\times$ & $x$ & $\times$ \\
\hline
\end{tabular}

OGood injection molding $\triangle$ Just short molding $\times$ Short molding

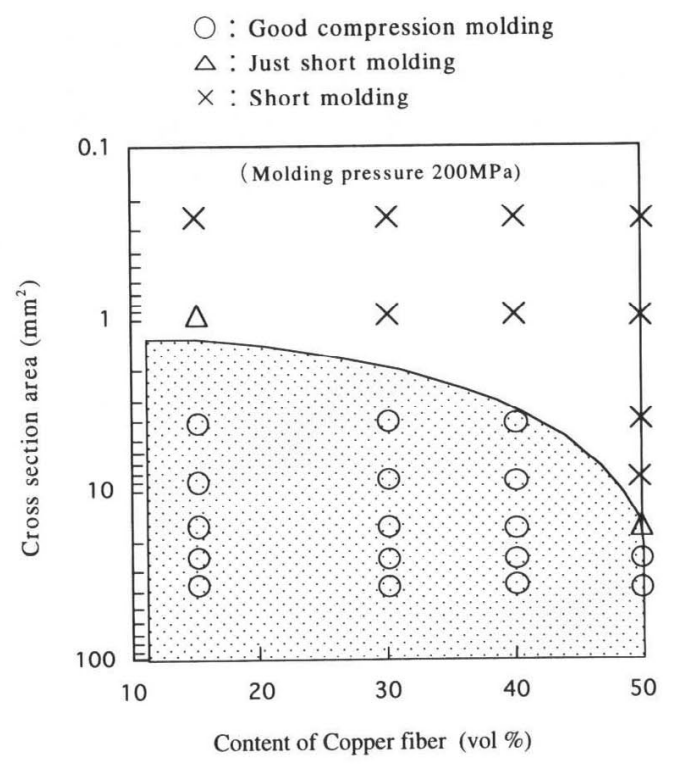

Fig. 7 Molding limit diagram under conditions of cross section area and content of copper fiber 


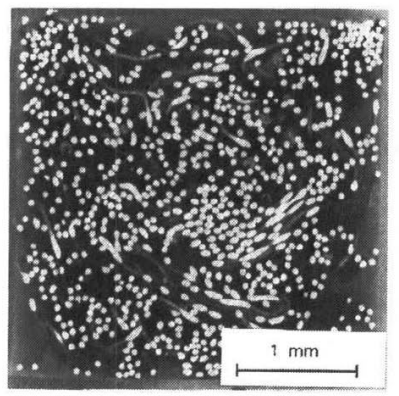

$16.2 \mathrm{vol} \%$

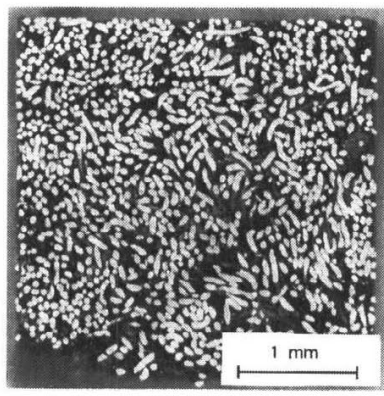

$40 \mathrm{vol} \%$

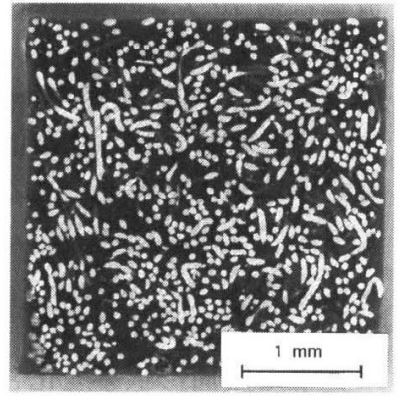

$30 \mathrm{vol} \%$

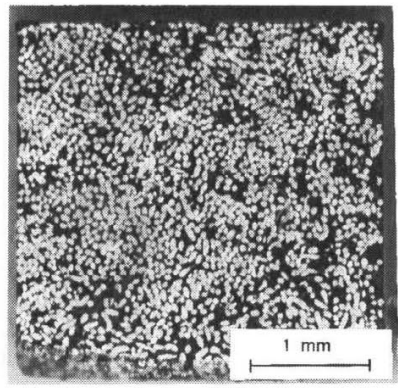

50 vol $\%$
Fig. 8 Distribution of fiber

はこの問題解決が不可欠と言える.

\section{6. 緎維分散状況の観察}

本研究における圧縮成形実験においては，成形速度や金 型温度など一般の射出成形とはかなり異なるものの，中央 部より材料は放射状に流れていく形をとっている，混入さ れた銅繊維は混練時に折れ曲がりお互いに絡み合っている。 圧縮成形時には繊維が接触しながら流動するため, 䋐維混 入量の増加にしたがい繊維の方向性はなくなるものと想定 される。これら瀻維の分散状況を調べる目的で成形体の断 面を観察した，その結果を四 8 に示す。これによれば，打 おむね瀻維は均一に分散しているものの，16 vol\%添加の 試料では繊維の分散に偏りが観察されるが，纎維混入量の 増加にしたがい均一化されている．さらに導電性を発現さ せるための繊維同士の接触筒所も混入量の増加にしたがい 多くなることが観察された。 また，繊維の方向性について も, 緎維の流動方向とその直角方向で多少の差は認められ るものの，はっきりした方向性は観察できなかった。これ
には, 混入した瀻維長さに比較して圧縮成形体の形状が小 さいため成形方法自体に余り方向性が現れないものである ことや，緎維の接触や絡み合いのために方向性がでにくい ためと考えられる。

\section{7. 結論}

電磁波シールド用の金属䋐維混入の導電性プラスチック と同様な手法により，金属瀻維混入量を混練限界まで増大 させ高導電性プラスチックを試作してみたところ以下のよ うな結論を得た。

1) 銅短瀻維と $\mathrm{ABS}$ 樹脂の組合せで，接合のためにはん だを添加し，混練する方法で，銅繊維含有率 $50 \mathrm{vol} \%$ ま での導電性プラスチックを得た。

2 ) 体積固有抵抗は銅繊維 $30 \mathrm{vol} \%$ 以上で $10^{-5} \Omega \cdot \mathrm{cm}$ オーダーの值が得られることがわかった。 また $50 \mathrm{vol} \%$ では $2.2 \times 10^{-5} \Omega \cdot \mathrm{cm}$ の值が得られた。

3) またこの導電材の圧縮成形体に通電しても抵抗值が低 いものは，発熱することはない。

4) しかし，圧縮成形に扮ける流動性はかなり低下し， $1 \mathrm{~mm}$ 角以下の細線は成形不可能なレベルで，太線でも 銅繊維 $50 \mathrm{vol} \%$ ものは圧縮成形が困難である.

5 ）䋐維混入率の低い市販導電性プラスチックでは, 試料 の測定部位により導電性に大きな違いが生じた。

6 ）銅緎維の分散状況は緎維混入率が多くなるにしたがい おおむね均一化されていたが，これに合わせ，導電性を 発現させるための銅瀻維の接触箇所も増大した。

\section{参 考 文 献}

1) 佐藤利夫：工業材料， 32(10)，62-68（1984）

2 ）長谷川正，鈴木㤁信：上業材料，30(10)，25-31 (1982)

3 ）柳沢 章, 中川威雄, 野口裕之：導電性材料をめぐる 最近の動向 (久保輝一郎, 石橋正嗣, 本多敏雄)，56 （1992）材料技術研究会

4）中川威雄，鈴木 清，植松哲太郎，小山浩幸：精密機 械, 47 (11)，1399-1405（1981）

5 ）中西清隆：日経ニューマテリアル，10(69)，40-54 (1989)

6 ）杉村宣雄，岩瀬英裕，小嶋政夫：成形加工，4（7), 403-410 (1992) 